\title{
Optimum Permanent Magnets Configuration in Flat-Quasi Linear Permanent Magnet Generators
}

\author{
Fransisco Danang Wijaya, Budi Azhari, Harnoko Stephanus
}

Department of Electrical Engineering and Information Technology, Gadjah Mada University, Yogyakarta, Indonesia

\begin{tabular}{l}
\hline \hline Article Info \\
\hline Article history: \\
Received Jul 27, 2016 \\
Revised Sep 20, 2016 \\
Accepted Oct 4, 2016 \\
\hline
\end{tabular}

Keyword:

Cogging force

Linear generator

Optimum configuration

Output power

\begin{abstract}
Flat-quasi type of linear permanent magnet generators (LPMGs) have been considered to be applied for several applications, such for wave energy conversion and free piston combustion engine. One of the important issues concerning LPMG is the permanent magnets configuration, due to its effects to the generator's excitation performance. In this paper, a $1 \mathrm{~kW}$ flat-quasi LPMG would be designed and built. During the process, optimum permanent magnets configuration was required and researched. The optimum configuration considered the output power and resulted cogging force. Invetigation was then conducted by modifying several variables, including poles' arrangement, pole length, number of pole, and pole skewing angle. The modification constraints were total permanent magnets' volume and generator dimension. The results showed that permanent magnet configuration with halbach arrangement, pole length equals $55 \%$ of the slot pitch length, and $61.19^{\circ}$ skewing angle produced the optimum output values.
\end{abstract}

Copyright $@ 2016$ Institute of Advanced Engineering and Science. All rights reserved.

\section{Corresponding Author:}

Budi Azhari,

Department of Electrical Engineering and Information Technology,

Universitas Gadjah Mada,

$2^{\text {nd }}$ Grafika street, Mlati, Sleman, Yogyakarta, Indonesia.

Email: budi.azhari@mail.ugm.ac.id

\section{INTRODUCTION}

Linear permanent magnet generators (LPMGs) have attracted interest of many scientists and engineers around the world [1]. This generator, as shown in Figure 1(a) have been used for many applications, such for sea wave energy conversion and free piston internal combustion engine [2-3]. The characteristics of the sea wave are having high peak force and low speed [4], which all support the use of this generator. Furthermore, unstable wave energy problems could be solved by utilizing energy storage system to maintain the output voltage and frequency [5]. On the other hand, the use of the LPMG in free piston combustion is considered due to its ability to produce higher combustion efficiency, higher power density, and work for various fuels [6].

Differ from common rotary model, LPMG generates electric energy by driving linear motion without any medium components, such as gears, screws, or crankshafts [7-8]. Generally, several advantages could be gained from this model, such as simpler structure, higher efficiency and longer lifetime compared to rotary ones [8]. Besides, the elimination of the medium components also reduces initial cost and simplifies the structure of the machine.

Based on the geometrical shape, linear generators could be separated into tubular-type and flat-type. Tubular type has cylindrical body, while the flat ones have prism shape. Recent studies show that for various load, flat-type LPMG have easier and cheaper design, and higher values of efficiency and output power than the tubular ones [9-10]. Furthermore, the use of permanent magnets for the generator excitation is because of its simpler design, higher flux density in air gap, and higher efficiency [11]. 
The flat-type LMPGs could be further classified based on the shape of its stator core. There are flat tricore which has triangular-shaped stator and flat-quasi with its rectangular-shaped stator [12]. Both types are shown in Figure 1(b). The last type has been proved to have larger flux density and induced voltage in various low speeds [12].

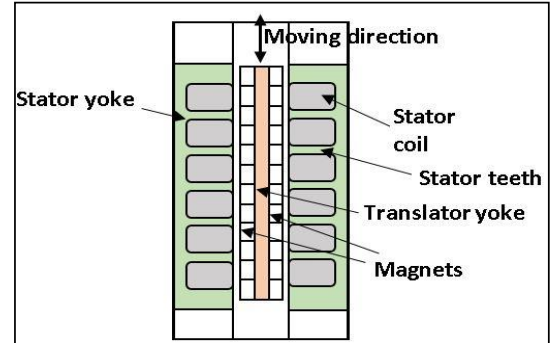

(a)

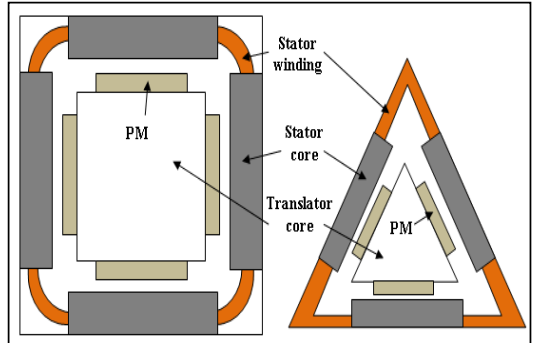

(b)

Figure 1. (a) Linear Permanent Magnet Generator (LPMG) Model and (b) Several Model of Flat Type Linear Generator: Flat-Tricore (left) and Flat-Quasi (right).

One of the important issues in all generators is the excitation system. This system would determine the output voltage and output power [13]. In permanent magnet generators, including LPMGs, the excitation performance is determined by configuration of the permanent magnets. Besides, the configuration of the permanent magnets could also contribute to disruptive output parameter's value, such as cogging force [14].

In this paper, a $1 \mathrm{~kW}$ flat-quasi LPMG would be designed and built. During the process, optimum permanent magnets configuration was required and investigated. To obtain the desired result, modeling and simulation were conducted. Those things, however are important for preliminary analysis, as they could reduce the cost and spending time of any research which means to design certain tools or systems [15]. The optimization in this case used pole modification method. The overall dimension of the machine was fixed, while the modification were applied to the permanent magnet units.

Previous researches have tried to find out the optimum design of linear permanent magnet generator. In tubular LPMG, optimization was conducted to obtain minimum electrical losses and maximum efficiency. It is performed by changing the length ratio of radial magnets and axially magnet, and the ratio of translator diameter and stator diameter [16].

Different tests had also been conducted to tubular LPMG. This tests were meant to optimize the output power, cogging force, and the weight of the machine [17]. In this case, several variables, such as the stator core height, air gap, magnets height, and the number of the pole were tested based on the 2D model of the machine.

Other researcher investigated the optimum design on flat LPMG. The optimization was aimed to minimize the cogging force. The research only used commercially available permanent magnets Therefore the size of the magnets were fixed and the size modification was only applied to the teeth and slot. Several variables, such as magnet and gap dimension, magnet skewing angle, and semislot dimension were modified and tested [18].

All researches above investigated the optimum design of the LPMG. However, there are different variables and/or optimized parameters among those researches. In this paper, the optimization was focused on the permanent magnet variables, and was meant to optimize the output power and cogging force. The variables that were modified are the arrangement, unity length, number, and skewing angle of the permanent magnets. The total volume of the permanent magnets, translator, and the overall dimension of the machine were kept constant.

First, a three phase $1 \mathrm{~kW}$ flat-quasi LPMG model was presented. The model was then simulated using Finite Element Method (FEM) software of FEMM. During the simulation, the configuration of the permanent magnet was modified. In each test, the output power and resulted cogging force were examined and noted. The configuration that produces maximum output power and minimum cogging force was chosen for the next tests. At the end of the paper, the optimization result was examined and discussed. 


\section{RESEARCH METHOD}

\subsection{Proposed LPMG Model}

A $1 \mathrm{~kW}$ flat-quasi LPMG was modeled. In this paper, two-sided LPMG, as shown in Figure 2 (a), representing four-sided LPMG, as shown in Figure 2(b). Permanent magnets for excitation were placed on the translator, while the electrical output could be extracted from the stationary part (stator). The permanent magnets were made of rare-earth material ( $\mathrm{NdFeB} 40)$ and were initially arranged in radial arrangement. This initial arrangement of the permanent magnet was illustrated in Figure 3.

The stator had salients on its end. These salients were aimed to maximize the flow of the magnetic flux from the magnets and to reduce the cogging force [19]. American Wire Gauge (AWG) 11 was used as the stator wire, because expected full load current that could be generated from the LPMG was 10 A. Furthermore, the stator winding used concentrated winding model.

Several equations were considered to design this generator [20]. The power rating of the generator was approached using the following equation,

$$
P=m \cdot V_{T} . I
$$

The value of expected terminal voltage, $\mathrm{V}_{\mathrm{T}}$ next lead to the value of expected electromotive force (emf), by using the following equation,

$$
E_{A}=V_{T}+I(R+j X)
$$

Then, the value of the emf was used to determine the width of the stator. The equation is shown below,

$$
W_{s}=\frac{E_{A} \sqrt{2}}{M_{s} \cdot N_{t} \cdot B_{T} \cdot v_{a v g}}
$$

Meanwhile, the desired value of rated current would determine the size of coil wire. For certain kind of wire with typical diameter, the size of slot follows the equation below,

$$
s_{l}=\frac{\pi\left(\frac{D}{2}\right)^{2} \cdot N_{t}}{0.6 \cdot s_{w t}}
$$

The actual width of air gap could be determined using equation below,

$$
g_{e q}=K_{C} \cdot g
$$

where $\mathrm{K}_{\mathrm{C}}$ is Carter coefficient. The value of $\mathrm{K}_{\mathrm{C}}$ could be calculated using equation below.

$$
K_{C}=\frac{\tau_{t}\left(5 g+s_{w t}\right)}{\tau_{t}\left(5 g+s_{w t}\right)-s_{w t}^{2}}
$$

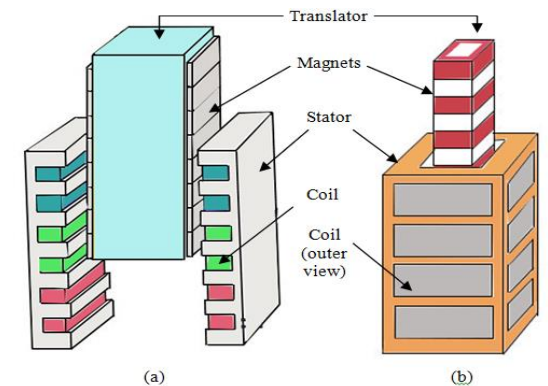

Figure 2. (a) Two-Sided Flat LPMG; (b) Four-Sided Flat LPMG. 
Table 1. Parameter Data of LPMG Model

\begin{tabular}{cccc}
\hline Symbol & Quantity & Unit & Value \\
\hline $\mathrm{L}_{\mathrm{s}}$ & stator total length & $\mathrm{mm}$ & 330 \\
$\mathrm{~W}_{\mathrm{s}}$ & stator width & $\mathrm{mm}$ & 120 \\
$\mathrm{t}_{\mathrm{l}}$ & stator teeth length & $\mathrm{mm}$ & 90 \\
$\mathrm{t}_{\mathrm{w}}$ & stator teeth width & $\mathrm{mm}$ & 20 \\
$\mathrm{~S}_{\mathrm{w}}$ & salient width & $\mathrm{mm}$ & 30 \\
$\mathrm{~S}_{\mathrm{h}}$ & salient height & $\mathrm{mm}$ & 10 \\
$\mathrm{~S}_{\mathrm{l}}$ & slot length & $\mathrm{mm}$ & 80 \\
$\mathrm{~S}_{\mathrm{wt}}$ & slot width & $\mathrm{mm}$ & 30 \\
$\tau_{\mathrm{t}}$ & slot pitch & $\mathrm{mm}$ & 50 \\
$\tau_{\mathrm{p}}$ & pole length & $\mathrm{mm}$ & 27.5 \\
$\tau_{\mathrm{w}}$ & pole thickness & $\mathrm{mm}$ & 20 \\
$\mathrm{~S}_{\mathrm{bw}}$ & stator back iron width & $\mathrm{mm}$ & 30 \\
$\mathrm{~S}_{\mathrm{o}}$ & slot opening & $\mathrm{mm}$ & 20 \\
$\mathrm{~m}$ & number of phase & - & 3 \\
$\mathrm{p}$ & number of pole & - & 12 \\
$\mathrm{q}$ & slot/pole/phase & - & 0.5 \\
$\mathrm{H}_{\mathrm{c}}$ & PM coercivity & $\mathrm{A} / \mathrm{m}$ & 979,000 \\
$\sigma$ & PM electrical conductivity & $\mathrm{MS} / \mathrm{m}$ & 0.667 \\
$\mathrm{~N}_{\mathrm{t}}$ & turns per slot & - & 300 \\
$\mathrm{~B}_{\mathrm{r}}$ & $\mathrm{PM}$ magnetic flux density remanant & $\mathrm{T}$ & 1.24 \\
$\sigma-\mathrm{s}$ & stator wire electrical conductivity & $\mathrm{MS} / \mathrm{m}$ & 58 \\
$\mathrm{D}$ & stator wire diameter & $\mathrm{mm}$ & 0.20378 \\
$\mathrm{R}$ & stator wire resistance & $\Omega / \mathrm{km}$ & 4.13 \\
\hline
\end{tabular}

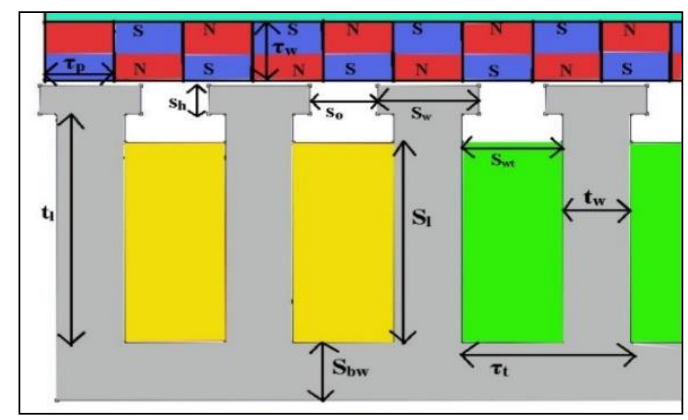

Figure 3. One-Sided of flat-quasi-type LPMG model with radial configuration.

Slot pitch $\left(\tau_{\mathrm{t}}\right)$ is defined as the length of slot width $\left(\mathrm{s}_{\mathrm{wt}}\right)$ plus the length of tooth width $\left(\mathrm{t}_{\mathrm{w}}\right)$. After deciding its value, the length of stator could be calculated using the following equation:

$$
L_{s}=\tau_{t} \cdot p \cdot q \cdot m+t_{w}
$$

The value of pole length $\left(\tau_{\mathrm{p}}\right)$ then could be calculated using the following equation.

$$
\tau_{P}=\frac{L_{s}}{p}
$$

More detail information about the generator model is shown in Table 1, which refers to Figure 3. Finite element method with open source software FEMM was then used. This software could be controlled by Lua scripts to extract desirable quantities, such as flux linkage and resulted cogging force [21]. In this paper, the simulation was conducted in two-sided model. However, the results of the induced voltage and cogging force values of the four sided design were assumed linear with the two sided's. The initial design of the generator in FEMM is shown in Figure 4 (right).

\subsection{Optimization Procedure}

After modeling and simulating the desired LPMG model, the permanent magnets configuration was then modified. The modification was conducted sequentially. First, the pole arrangement was modified. Then the pole length was modified while keeping the total length and volume of the translator. After that, the magnets were skewed with certain skewing angle. When the magenets were skewed, the size of each magnet was also kept constant. In each modification, the optimum design was determined by using a fitness function. 
The output power was noted at full load condition. For obtaining the output power, single phase analysis could be conducted. First, no-load induced voltage for each phase was examined. In this test, the simulation only gave the flux linkage values. The Faraday's law equation could be used to convert that value to induced voltage value.

$$
\varepsilon=\frac{d \lambda}{d t}=\frac{d \lambda}{d z} \cdot \frac{d z}{d t}=\frac{d \lambda}{d z} \cdot v(t)
$$

where variable $\mathrm{v}(\mathrm{t})$ shows that the velocity is time-varying. However, in this paper, the velocity was assumed contant.

Table 2. Meaning of Several Symbols Used in this Paper

\begin{tabular}{lll}
\hline Symbol & \multicolumn{1}{c}{ Meaning } & Unit \\
\hline$\varepsilon$ & no-load induced voltage & $\mathrm{V}$ \\
$\lambda$ & flux linkage & $\mathrm{Wb}$ \\
$\mathrm{t}$ & time variable & $\mathrm{s}$ \\
$\mathrm{Z}$ & translation position & $\mathrm{m}$ \\
$\mathrm{v}$ & translation speed & $\mathrm{m} / \mathrm{s}$ \\
$\mathrm{Z}$ & coil impedance & $\Omega$ \\
$\mathrm{I}$ & full load current & $\mathrm{A}$ \\
$\mathrm{R}_{\mathrm{L}}$ & load resistance & $\Omega$ \\
$\mathrm{X}$ & coil reactance & $\Omega$ \\
$\mathrm{f}$ & frequency & $\mathrm{Hz}$ \\
$\mathrm{L}$ & coil inductance & $\mathrm{H}$ \\
$\mathrm{R}_{\text {line }}$ & coil resistance & $\Omega$ \\
$\mathrm{P}_{\mathrm{T}}$ & output power & $\mathrm{W}$ \\
$\mathrm{n}$ & constant for deciding the output frequency & - \\
$\mathrm{P}$ & output power from simulation & $\mathrm{W}$ \\
$\mathrm{F}_{\mathrm{C}}$ & output cogging force from simulation & $\mathrm{N}$ \\
$\mathrm{P}_{\min }$ & minimum output power from certain test & $\mathrm{W}$ \\
$\mathrm{F}_{\mathrm{C} \_ \text {max }}$ & maximum cogging force from certain test & $\mathrm{N}$ \\
\hline
\end{tabular}

Assuming that there was only resisitive load of $\mathrm{R}_{\mathrm{L}}$, the value of load resistance could be determined.

$$
R_{L}=\sqrt{\left(\frac{\varepsilon}{I}\right)^{2}-X^{2}}-R_{\text {line }}
$$

The value of $\mathrm{X}$ was determined by the output frequency. It could be calculated using equation below.

$$
X=2 . \pi . f . L
$$

Meanwhile, the output electrical frequency was analytically affected by the pole configuration.

$$
f=\frac{v}{n \tau}
$$

The value of $n=4$ for halbach magnetic array $n=2$ for radial or axial magnetic array. Meanwhile, the value of line resistance could be calculated using equation below.

$$
R_{\text {line }}=2 \cdot \pi \cdot \tau_{t} \cdot N_{t}+2\left(W_{s}+s_{b w}+t_{l}+s_{h}+g+\tau_{w}\right)
$$

Usually, second term is relatively small compared to first term, thus its effect is not significant. The full load output power was then calculated by using equation below.

$$
P_{T}=3 . I^{2} \cdot R_{L}
$$

Equation (10) and (14) has urged to set the maximum current below the full load current in case the full load current was less than $10 \mathrm{~A}$. If both values are equal, the value of $\mathrm{R}_{\mathrm{L}}$ would be zero and so would the output power. In other words, all input power are dissipated in coil resistance as power loss. 
Another consideration was cogging force. It is undesired force that is resulted from the attractive interaction between permanent magnets in translator and stator teeth, which was made of ferromagnetic materials [22-23]. The presence of cogging force could cause mechanical oscillation during translator movement. Thus, the value of the cogging force should be minimized.

Single phase equivalent circuit in this test is shown in Figure 4 (left). Meanwhile, list of symbols used in this paper, complete with their meanings and units are in Table 2. Since three phase generator was used, there were self and mutual inductances. The total inductance was the sum of both inductances' values.

The effect of modification to the size of the generator and the investment cost were neglected. Earth's gravitation and air friction force were also neglected. The optimum design in each modification was chosen based on the value of fitness function (F) below. Larger the value of fitness function, a design was said to produce optimum or better output.

$$
F=\frac{P}{P_{\min }}-\frac{F c}{F c_{\max }}
$$
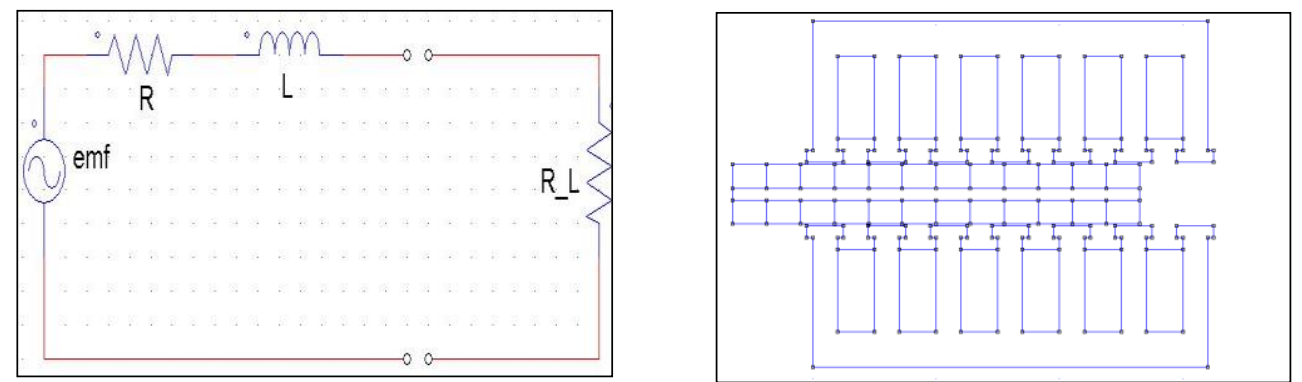

Figure 4. Single Phase Equivalent Circuit of the LPMG Model (left); Generator Model in FEMM (right)

\section{RESULTS AND ANALYSIS}

\subsection{Optimum Poles' Arrangement}

As mentioned earlier, the initial configuration at first using radial permanent magnets arrangement. The arrangement was then varied, while other parameters' values were kept constant. Overall, the configurations used in this test were radial, axial, and halbach. All of these arrangements are shown in Figure 5(a)-5(c).

Radial arrangement in this configuration was shown in the left side of Figure 5(a). In this arrangement, two adjacent magnets have alternating magnetization, with one points out the stator and another points out the opposite direction. This arrangement is relatively simple and low-cost assembly. However, for more than one-sided permanent magnet arrays, magnetic yoke is needed to maintain the distance among those arrays. This yoke would then cause several consideration, such as eddy current loss and increase of the generator weight.

Axial arrangement in this configuration was shown in Figure 5(b). It does not have to be sticked on magnetic yoke. In this arrangement, each magnet have magnetization that is perpendicular to the surface of the stator teeth. The adjacent magnets would naturally repel each other due to their magnetization setting, so they might be tied to hold their position. This arrangement could be assembled with or without any distance pieces between two magnets.

The magnetic field resulted from radial and axial magnetic arrays are shown in the right side of Figure 5(a) and Figure 5(b) successively. It could be seen that both arrangement result magnetic field in both sides of each array. The consequences is that the magnetic field through the yoke would be quite large, which then generates quite large eddy current losses. Besides, the magnetic flux that flows to the coil would decrease, so the output power would not be optimum.

Halbach arrangement in this configuration is shown in the left side of Figure 5(c). It consists of alternating radial and axial magnets. In this case, there are four directions of magnetization, which yield nearly sinusoidal magnetic flux output. Moreover, this configuration would augment the magnetic field on one side of the permanent magnets array, and cancel the field up to nearly zero on the other side. This array properties could increase the efficiency of the generator, since the magnetic flux from the permanent magnets could be focused to one side. However, the investment cost of this arrangement is quite high. 
The magnetic field from halbach arrangement is shown in the right side of Figure 5(c). In this arrangement, the magnetic field through the magnetic yoke is lesser than the previous arrangements. Therefore, this arrangement could reduce the eddy current loss. Moreover, the magnetic flux that flows to stator would be larger than the previous arrangement. It would then increase the induced voltage and the output power of the generator.
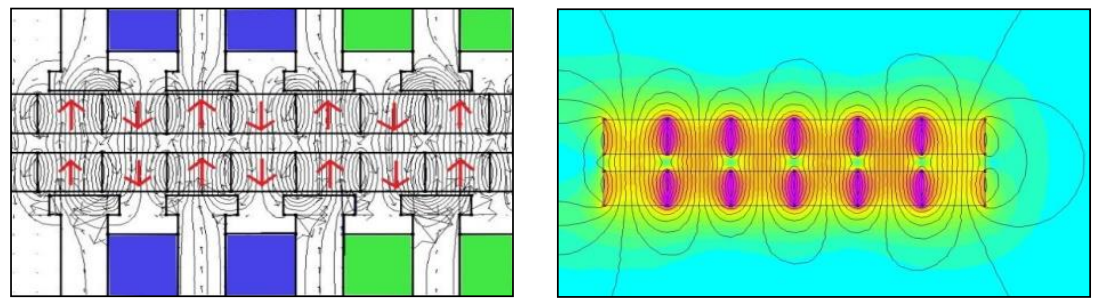

(a)
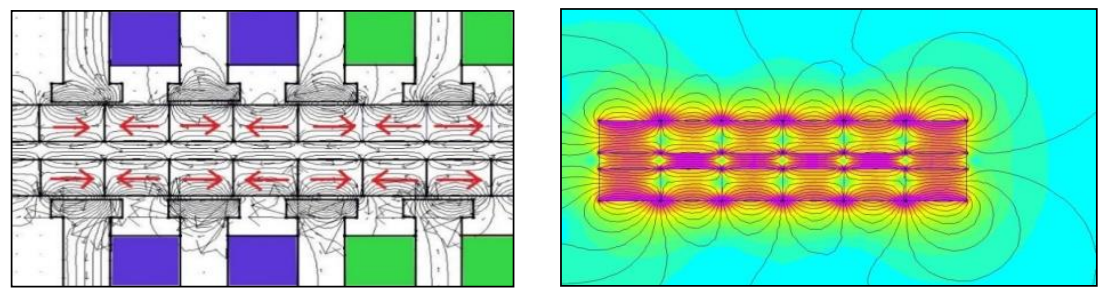

(b)
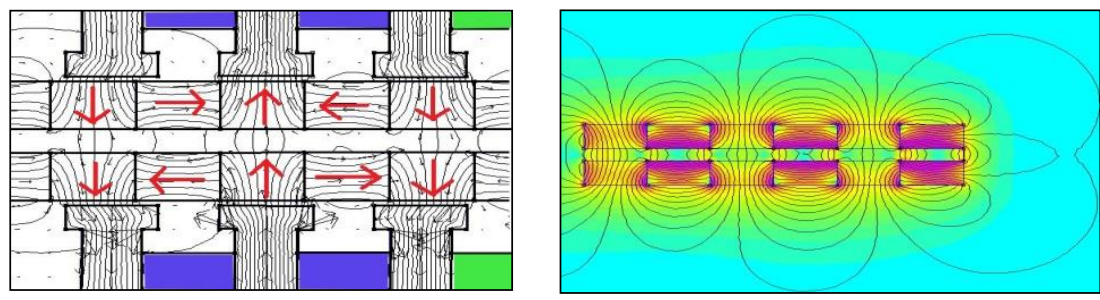

(c)

Figure 5. Arrangement Model: (a) Radial, (b) Axial, (c) Halbach.

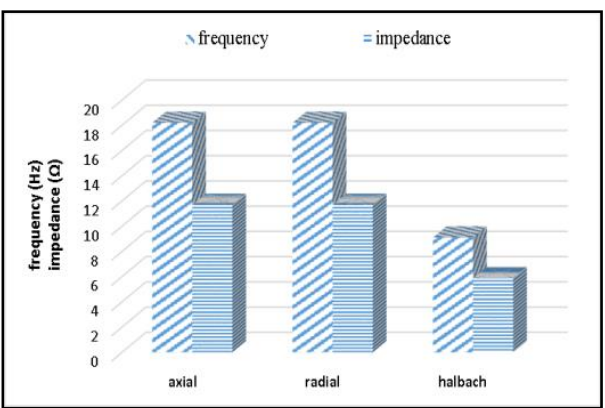

Figure 6. Frequency and Impedance of Various Arrangement

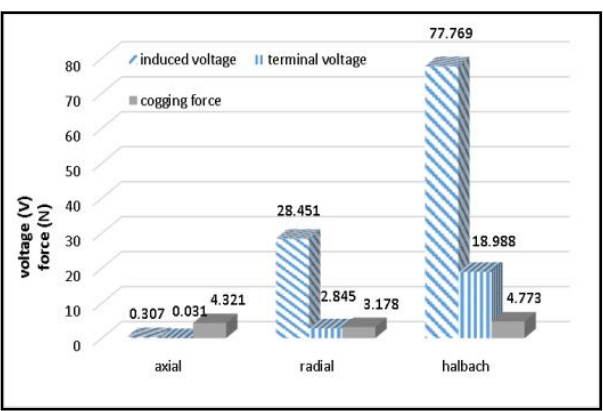

Figure 7. The Values of Induced Voltage, Terminal Voltage, and Cogging Force from Various Arrangement 


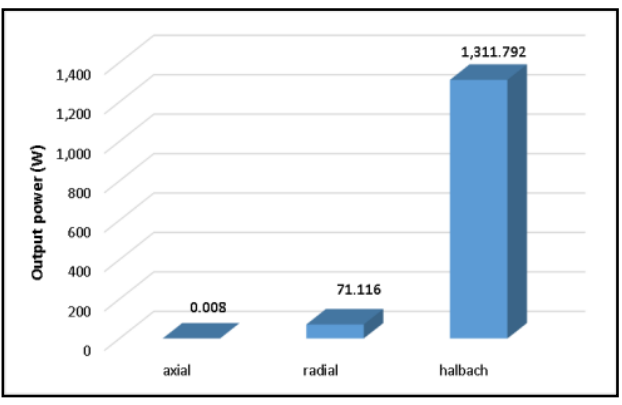

(a)

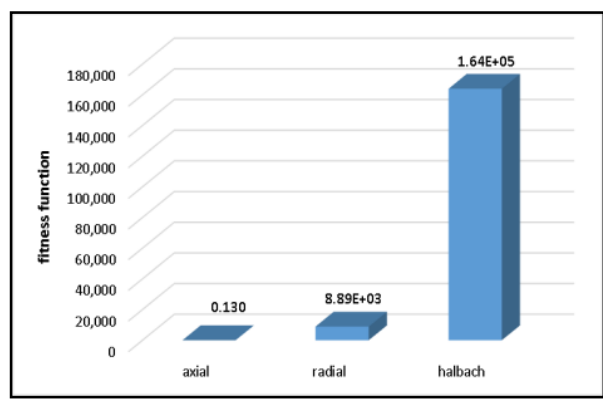

(b)

Figure 8. (a) Output Power, and (b) Fitness Function of Various Configuration

The simulation used $1 \mathrm{~m} / \mathrm{s}$ as the translation speed, and was assumed constant. In halbach arrangement, one period of electrical wave would be generated in coil after four adjacent poles passing a stator tooth where that coil lies. Meanwhile in both radial and axial array, same amount of wave could be generated after two adjacent poles passing the tooth. Because the translation speed was same for all arrangements, then the electrical frequency resulted from halbach arrangement would less than the electrical frequency of both axial and radial arrangement. The electrical frequency then determines the inductance, reactance, and thus impedance of the coil. The frequency and the impedance of all arrangement are shown in Figure 6. Halbach arrangement results lower electrical frequency, thus lower impedance than the other two arrangements.

On the other hand, focussed magnetic flux of halbach array induces larger voltage than the other arrays. Then with lower coil impedance, the terminal voltage of the halbach array would become the largest, and so is the output power. The values of the induced voltage and output power of all arrangements are shown in Figure 7 and Figure 8(a) respectively.

The arrangement also affect the cogging force. From Figure 7, halbach arrangement suffers the largest cogging force. This is due to the strongest magnetic field resulted from this arrangement, compared to the other two. On the other hand, radial arrangement suffers the lowest. In this arrangement, the accumulation of the flux density on the edges of the permanent magnet decreases.

From Figure 8(b), halbach arrangement produces the largest fitness function. In other words, this arrangement gives the optimum output. This configuration would then be used as initial configuration for next tests.

\subsection{Optimum Pole Length}

The dimension of the pole at first followed what are mentioned in Table 1. Then the value of pole length per slot pitch length $\left(\tau_{\mathrm{p}} / \tau_{\mathrm{t}}\right)$ was varied, with other parameters' values were kept constant. Because the translator total length and the magnets' total length and volume were kept, the change in pole length was then compensated by changing the number of poles. Longer the pole length $\left(\tau_{\mathrm{p}}\right)$, the number of the pole would be fewer, and vice versa. Furthermore, the initial translation speed in this test was set $1 \mathrm{~m} / \mathrm{s}$.

The results show that the value of $\tau_{\mathrm{p}} / \tau_{\mathrm{t}}$ would affect the value of the induced voltage and terminal voltage, as shown in Figure 10(a). The length of each permanent magnet affects the relative position of any magnet toward the stator. It then affects the instantaneous value as well as the rate of change of the flux linkage in the coil. The latter parameter, would determine the value of induced voltages.

The length of the magnet on the other hand, is inversely proportional to the output electrical frequency. This frequency would then affect the impedance of the coil. Figure 11(a) shows the values of the electrical frequency and the coil impedance for various values of $\tau_{\mathrm{p}} / \tau_{\mathrm{t}}$. The values of the induced voltage and coil impedance would determine the terminal voltage, which is directly proportional to the output power of the generator.

The length and number of the magnets also determines the cogging force, as shown in Figure 10(b). In this case, if each magnet has equal size, thus they produce equal magnetic field. Moreover the total translator volume and length were also constant. However, different size of single magnet results in different cumulative interactions in an array, and thus different force resultant. Then the average cogging force would differ among different pole length, for equal total length. 
The interaction which shows the cogging force could be described through the magnetic flux's lines which are resulted from each configuration. More intense the continuous flux's lines from the magnet to the stator teeth means stronger the interaction. However, the average cogging force value in this paper considers the interaction at all positions. So, the magnetic flux intensity in all relative position (during the translator movement) of the translator and stator would influence the result. Figure 9(a) to 9(d) shows the different magnetic flux's lines and intensity among several configuration at the same position.

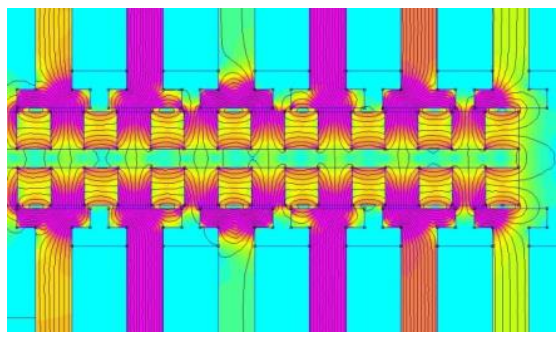

(a)

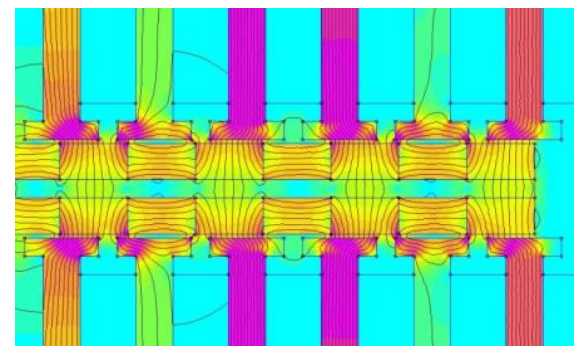

(c)

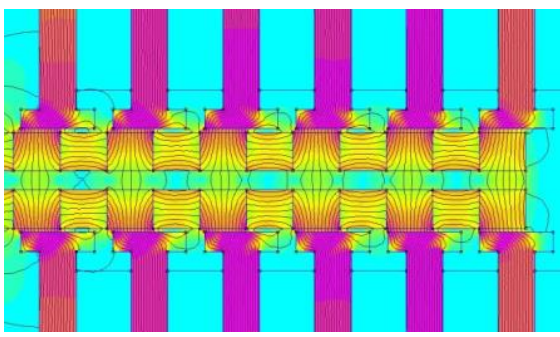

(b)

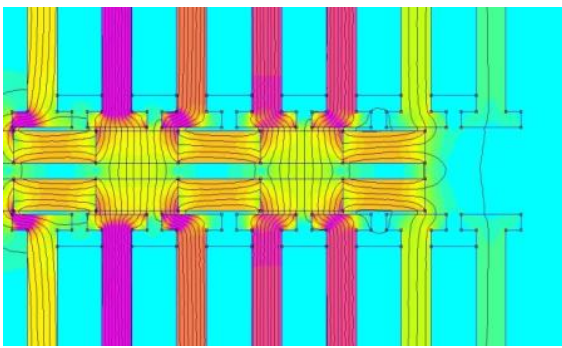

(d)

Figure 9. Different Magnetic Flux Intensity Relates to the Strength of Interaction of Flat-Quasi LPMG with, (a) 18 Poles; (b) 13 Poles; (c) 9 Poles; (d) 6 Poles, at same Position

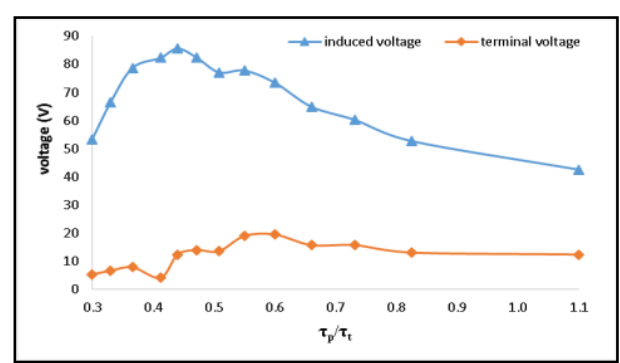

(a)

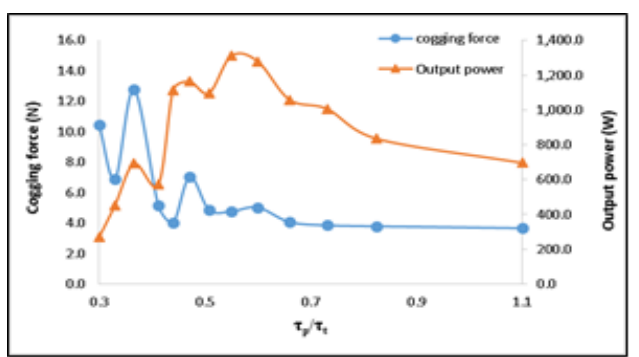

(b)

Figure 10. (a) Values of Induced Voltage and Terminal Voltage for Various $\tau_{\mathrm{p}} / \tau_{\mathrm{t}}$; (b) Values of Output Power and Cogging Force for Various $\tau_{\mathrm{p}} / \tau_{\mathrm{t}}$.

Figure 10(b) also shows that the configuration where the pole length equals $2.75 \mathrm{~cm}$ or $\tau_{\mathrm{p}} / \tau_{\mathrm{t}}=0.55$ results the largest fitness function. Then different values of translation speed were tested. It is purposed to check its influence to the value of fitness function. The results were tabulated in Figure 11(b). It could be seen that larger the value of the translation speed, the value of the fitness function would increase. However, the trend of the fitness function values are same for every value of speed. Figure 11(b) shows that the optimum output was obtained when $\tau_{\mathrm{p}}=2.75 \mathrm{~cm}$ or $\tau_{\mathrm{p}} / \tau_{\mathrm{t}}=0.55$, for all values of translation speed.

Further tests were then conductedby modifying some other parameters. In these test, the width of stator tooth's salient and the pole thickness were modified. In several values of the both quantities, all values 
of $\tau_{\mathrm{p}} / \tau_{\mathrm{t}}$ were re-tested. The results were then tabulated and compared. These tests were meant to check whether these two parameters affect the output values. This is because these two dimension in this test were decided manually.

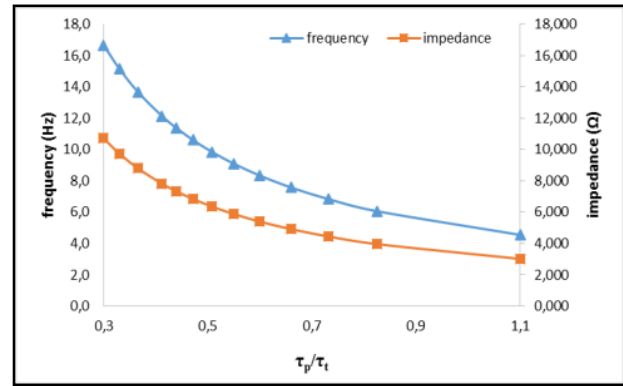

(a)

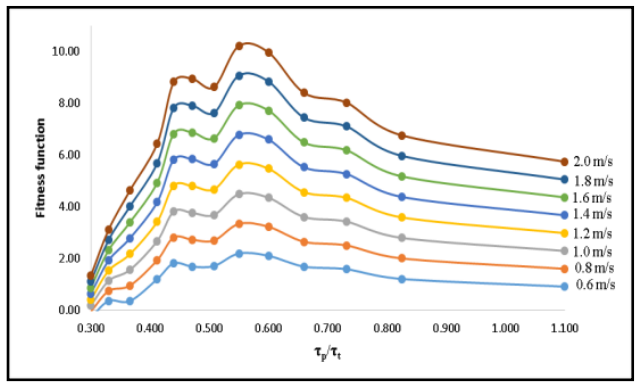

(b)

Figure 11. (a) Values of Resulted Electrical Frequency and Coil Impedance for Various $\tau_{\mathrm{p}} / \tau_{\mathrm{t}}$; (b) Values of Fitness Function for Various $\tau_{\mathrm{p}} / \tau_{\mathrm{t}}$ and for Several Values of Translation Speed.

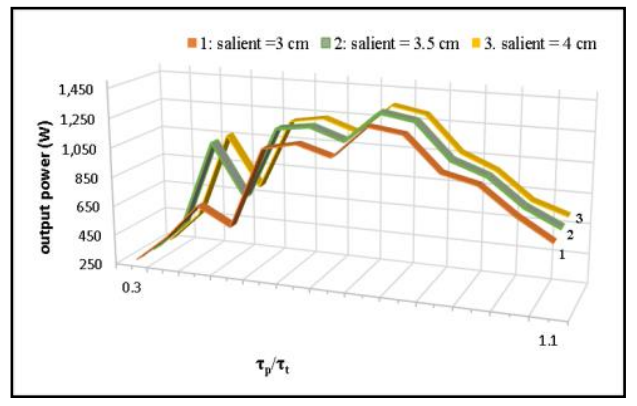

(a)

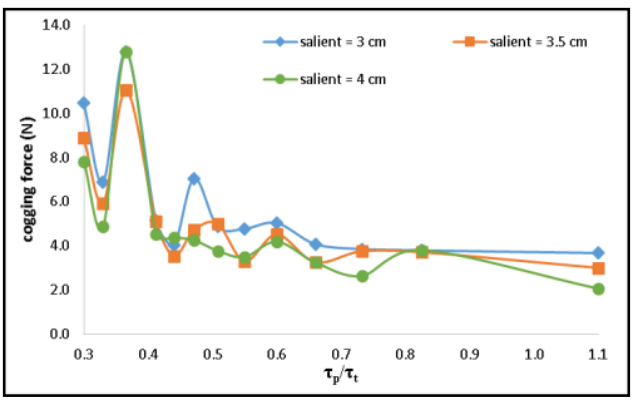

(b)

Figure 12. (a) Output Power and (b) Cogging Force Values from Various Values of $\tau_{\mathrm{p}} / \tau_{\mathrm{t}}$ and Different Salient Width.

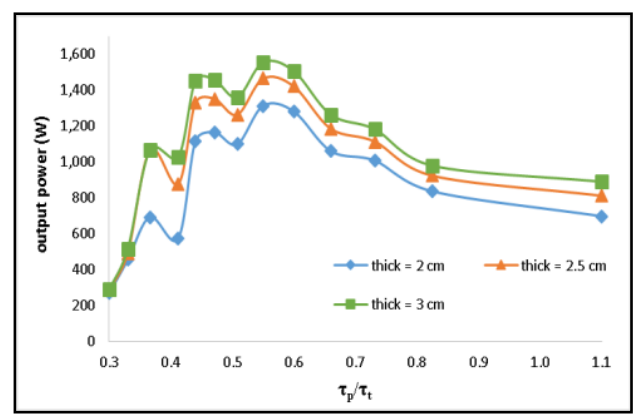

(a)

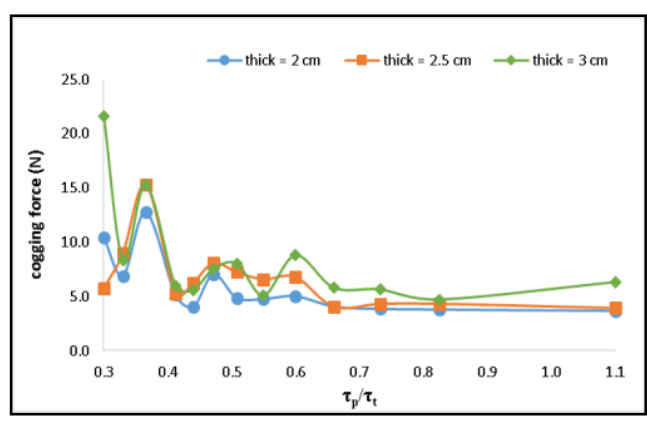

(b)

Figure 13. (a) Output power and (b) cogging force values from various $\tau_{\mathrm{p}} / \tau_{\mathrm{t}}$ and different pole thickness

The output power and cogging force values from several values of salient width are shown in Figure 12(a) and 12(b). Meanwhile, the values both parameters for several values of pole thickness are shown in Figure 13(a) and 13(b). From those graphs, the output power is directly proportional to the width of salient and pole thickness. However, the trend of the output power is same for all values of thickness. 
Meanwhile the cogging force slightly decreases if the width of salient is increase and slightly increases if the pole thickness increases.

If the fitness function values from all salient widths and pole thicknesses are tabulated, the result is shown in Figure 14. From that graph, the trend and the values of the fitness function is nearly same for all values of both quantities. Besides, Figure 14 also shows the pole length equals $2.75 \mathrm{~cm}$ or $\tau_{\mathrm{p}} / \tau_{\mathrm{t}}=0.55$ produces the largest fitness function, for all values of both quantites. This configuration, with initial value of salient width and pole thickness would be used for next test.

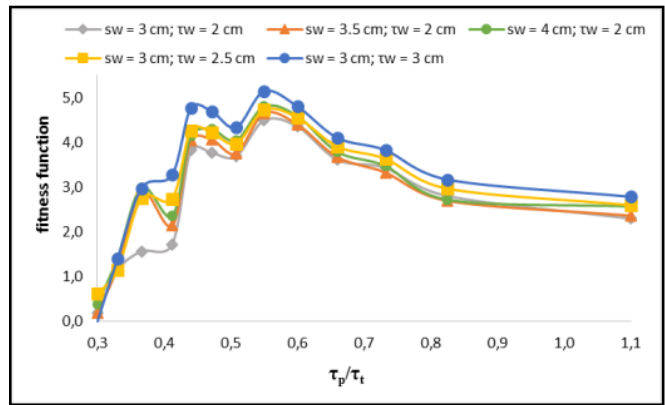

Figure 14. Fitness Function from Various Values of $\tau_{\mathrm{p}} / \tau_{\mathrm{t}}$.

\subsection{Optimum Pole Skewing}

The optimum configuration from previous test was brought for skewness test. Here, the permanent magnets were skewed with certain angles. However, other parameters' values were still kept constant. The illustration of the skewed poles is shown in Figure 15.

In this test, input variable of the skewing angle was set by shifting the outer side of the permanent magnets, each by $1 \mathrm{~mm}$. The skewing of the permanent magnets by this method would not change the total volume of the translator. However, the skewing might change the total length of the translator and modify its shape, which may need certain treatment in certain application. The skewing would also change the total surface area of the magnetic array. In this case, the skewing angles that were applied were limited between $45^{\circ}$ to $90^{\circ}$

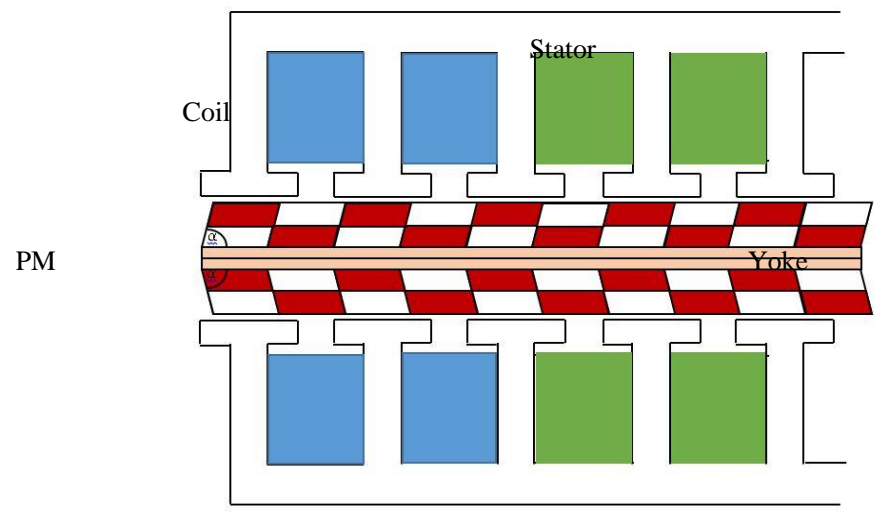

Figure 15. Illustration for Skewed Permanent Magnets

The change of surface area of the magnetic arrays would affect the induced voltage and cogging force. Different surface area, as well as shape, would affect the intensity of the magnetic flux that is resulted by the permanent magnets. On the other hand, the contact area between the magnet and the stator would also change for different skewing angle. Figure 16(a) shows the values of induced voltage and output power for several skewing angles. Meanwhile, the resulted cogging force and the fitness function are shown in and Figure 16(b). 
As it could be seen, the output voltage at first increases as the skewing angle decreases. It then reaches peak value at skewing angle $=63.44^{\circ}$, before going down as the skewing angle decreases. In this modification, change in skewing angle does not change the output frequency. This is because neither pole number nor pole length changes. Hence, the impedance of the coil is also constant. Then the output power is directly proportional to the induced voltage. It is proved from the trend of the output power which is same as the trend of induced voltage.

From Figure 16(b), the value of fitness function is inversely proportional to the value of cogging force. It could be seen that the trend of the fitness function is the reflection of the cogging force's trend. This result is valid in other designs with same treatment. It could be concluded that for an LPMG with skewed permanent magnet and for given fitness function, the trend of the cogging force is the reflection of the fitness function trend.

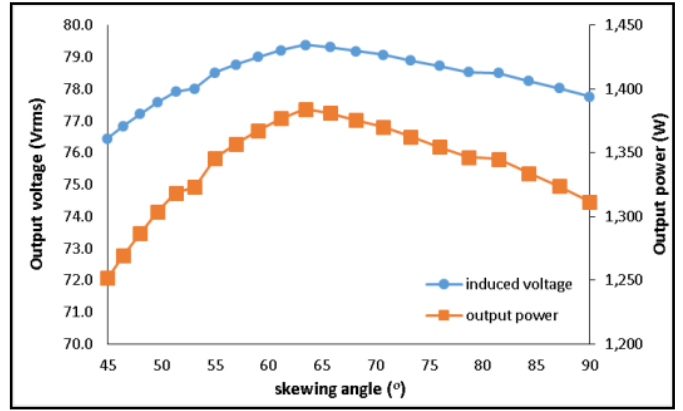

(a)

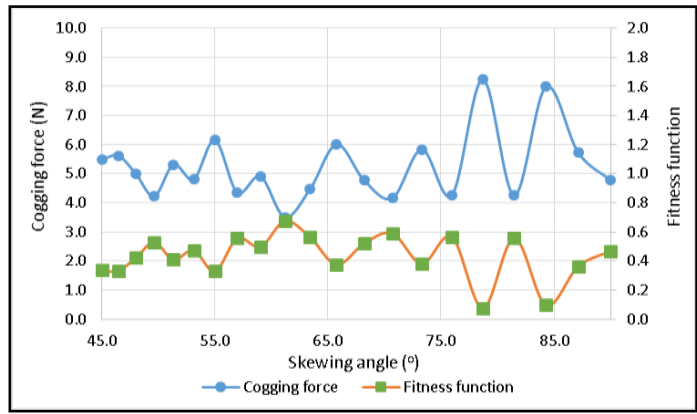

(b)

Figure 16. (a) Induced Voltage and Output Power from Various Skewing Angle; (b) Cogging Force and Fitness Function Values from Various Skewing Angle

In this test, the configuration where skewing angle equals $61.19^{\circ}$ results the optimum output. This configuration was then declared as the optimum one. The parameter values of the optimum configuration are tabulated in Table 3.

Table 3. Parameters' Values of Resulted Optimum Configuration of $1 \mathrm{~kW}$ Flat-quasi LPMG

\begin{tabular}{ccc}
\hline Parameters & Unit & Value \\
\hline Induced voltage & $\mathrm{V}_{\mathrm{rms}}$ & 79.225 \\
Coil resistance & $\Omega$ & 0.778 \\
Coil reactance & $\Omega$ & 5.826 \\
Coil impedance & $\Omega$ & 5.878 \\
Rated current & $\mathrm{A}$ & 10 \\
Terminal voltage & $\mathrm{V}_{\mathrm{rms}}$ & 20.445 \\
Frequency at rated speed & $\mathrm{Hz}$ & 9.091 \\
Output power & $\mathrm{W}$ & $1,376.999$ \\
Cogging force & $\mathrm{N}$ & 3.508 \\
PM skewing angle & - & $61.19^{\circ}$ \\
\hline
\end{tabular}

\section{DISCUSSION}

The optimization test was conducted for $1 \mathrm{~kW}$ flat-quasi LPMG design. The initial design of the generator considered several parameters and equations which are commonly used for designing typical machine. Furthermore, the optimization was focused on the permanent magnets of the generator.

In part of poles arrangement analysis, the dimension of the permanent magnets in each arrangement was same. This causes the number of the pole in each arrangement was same. In other words, this part only analyzed the arrangement, and not also investigated the number of the permanent magnet.

In pole length and pole number optimization analysis, it should be noted that the stator and the translator in this paper have equal length. Moreover, the modification did not change both total surface area 
and volume of the permanent magnets. It would be beneficial to further investigate the effect of these two parameters if the translator length is not constant.

In pole skewing angle analysis, the skewing angle was limited from $45^{\circ}$ to $90^{\circ}$. Larger angle is impossible to design. Meanwhile, smaller angle is not recommended due its uncommon design, manufacture difficulties, and larger cost of manufacturing.

Other similar optimization researches of LPMG have also conducted. However, those researches investigated either different objective parameter, or different method of optimization. Therefore, this research could be an additional reference for optimum design of LPMG.

\section{CONCLUSION}

The optimization of the permanent magnet's configuration for flat-quasi linear permanent magnet generator has been performed using $1 \mathrm{~kW}$ generator model. Pole modification methos was used to optimize the generator. The variables were the arrangement, pole length, and skewing angle of the permanent magnets. The constraints was the total permanent magnets' volume and size of the generator. The optimization considered the output power and resulted cogging force. It were shown that the permanent magnets with configuration of halbach arrangement, pole length equals $55 \%$ of the slot pitch length, and was skewed with skewing angle of $61.19^{\circ}$ resulted the optimum output. It was also proved that the salient width and the pole thickness might affect the output power and resulted cogging force. However, they did not affect the optimum level of the configuration based on given fitness function.

\section{REFERENCES}

[1] P. Wang, J. Si and C. Gao, "Research of Permanent Magnet Linear Generator for Wave Energy", Journal of Convergence Information Technology, vol. VII, no. 22, pp. 694-701, 2012.

[2] M. Prado and P. Henk, "Direct Drive in Wave Energy Conversion-AWS Full Scale Prototype Case Study", in IEEE Power and Energy Society General Meeting, San Diego, 2011.

[3] J. Chen, Y. Liao, C. zhang and Z. Jiang, "Design and Ananysis of a Permanent Magnet Linear Generator for a FreePiston Energy Converter", in IEEE 9th Conference on Industrial Electronics and Applications (ICIEA), Hangzhou, 2014.

[4] F. Bizzozero, M. Giassi, G. Gruosso, S. Bozzi and G. Passoni, "Dynamic Model, Parameter Extraction, and Analysis of Two Topologies of a Tubular Linear Generator for Seawave Energy Production", in International Symposium on Power Electronics, Electrical Drives, Automation and Motion, Ischia, 2014.

[5] R.N. Kumar and J. Baskaran, "Energy Management system for Hybrid RES with Hybrid Cascaded Multilevel inverter", International Journal of Electrical and Computer Engineering (IJECE), vol. IV, no. I, pp. 24-30, 2014.

[6] P. Sun, F. Zhao, C. Zhang, J. Zhang and J. Chen, "Dynamic Simulation of a Novel Free-Piston Linear Generator", in IEEE International Conference on Advanced Intelligent Mechatronics (AIM), Busan, 2015.

[7] S. Zulkifli and M. Ahmad, "Linear Generator Models in Simulink Block", in IEEE International Conference on Power and Energy, Kuala Lumpur, 2010.

[8] M.A.F.M. Hamim, T. Ibrahim and N.M. Nor, "Modeling and Analyze a Single-Phase Halbach Magnetized Tubular Linear Permanent Magnet Generator for Wave Energy Conversion", in International Conference on Power and Energy, Kuching, 2014.

[9] X. Niu, "Modeling and Design Analysis of a Permanent Magnet Linear Synchronous Generator", University of Illinois at Urbana-Champaign, Urbana and Champaign, 2013.

[10] Q.F. Li, J. Xiao and Z. Huang, "Flat-type permanent magnet linear alternator: A suitable device for a free piston linear alternator", Journal of Zhejiang University SCIENCE A, vol. X, no. 3, pp. 345-352, 2009

[11] C. Bode, H. Schillingmann and M. Henke, "A Free-Piston PM Linear Generator in Vernier Topology using quasiHalbach-Excitation", in International Conference on Electrical Machines, Berlin, 2014.

[12] A.H. Memon, T.B. Ibrahim and N. Perumal, "Portable and Pico-Scale Linear Generator for Wave Energy Conversion", in 5th International Conference on Intelligent and Advanced Systems, Kuala Lumpur, 2014.

[13] P. S. Kundur, Power System Stability and Control, 1st ed., Noida: McGraw-Hill, 1994.

[14] R. Krishna, O. Svensson, M. Rahm, S.K. Kottayil, R. Waters and M. Leijon, "Analysis of Linear Wave Power Generator Model with Real Sea Experimental Result", IET Renewable Power Generation, vol. VII, no. 5, pp. 574$581,2013$.

[15] M.N. Lakhoua, N. Walid and C. Atef, "System Analysis of a Hybrid Renewable Energy System", International Journal of Electrical and Computer Engineering, pp. 343-350, 2014.

[16] A.H. Memon, T.B. Ibrahim and P. Nallagowden, "Design Optimization of Linear Permanent Magnet Generator for Wave Energy Conversion", in IEEE Conference on Energy Conversion, Johor Bahru, 2015.

[17] F. Rinderknecht and H.G. Herzog, "Adaptation and optimization of a linear generator for a hybrid vehicle concept", World Electric Vehicle Journal, vol. IV, pp. 1-8, 2010.

[18] M. Trapanese, G. Cipriani, D. Curto, V.D. Dio and V. Franzitta, "Optimization of cogging force in a linear permanent magnet generator for the conversion of sea waves energy", in IEEE International Electric Machines \& Drives Conference, Idaho, USA., 2015. 
[19] H. Arof, A. Eid and K. Nor, "Cogging Force Reduction Using Special Magnet Design For Tubular Permanent Magnet Linear Generators", in Universities Power Engineering Conference, Bristol, 2004.

[20] R. Parthasarathy, "Linear PM Generator for Wave Energy Conversion", Louisiana State University, Baton Rouge, 2012.

[21] D.C. Meeker, Finite Element Method Magnetics, Version 4.2 (16Oct2010 Build), http://www.femm.info

[22] J. Faiz, M. Ebrahimi-Salari and G. Shahgholian, "Reduction of Cogging Force in Linear Permanent-Magnet Generators", IEEE Transaction on Magnetics, vol. XLVI, no. 1, pp. 135-140, 2010.

[23] N.M. Kimoulakis, A.G. Kladas and J.A. Tegopoulos, "Cogging Force Minimization in A Coupled Permanent Magnet Linear Generator for Sea Wave Energy Extraction Applications", IEEE Transaction on Magnetics, vol. XLV, no. 3, pp. 1246-1249, 2009.

\section{BIOGRAPHIES OF AUTHORS}

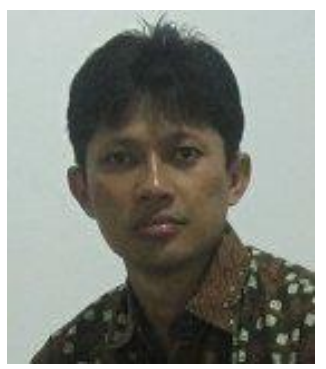

Fransisco Danang Wijaya, born on February 1974 in Sleman, Indonesia. He received his Bachelor and Master degree, both from Electrical Engineering Major, Gadjah Mada University in 1997 and 2001 respectively. He then got his Doctor of Engineering in Tokyo Institute of Technology in 2009. He is currently Associate Professor at the Department of Electrical Engineering and Information Technology, Gadjah Mada University. His research is specialized in power system engineering, energy conversion, also transmission and distribution system. He is also expert in power system control technique using Magnetic Energy Recovery Switch (MERS).

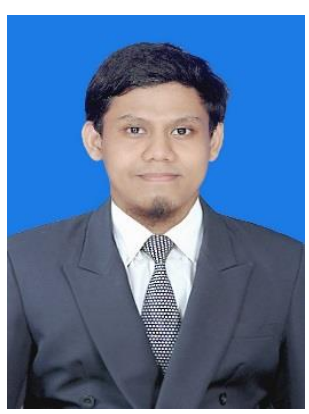

Budi Azhari was born on December 1994 in Bantul, Indonesia. He received his Bachelor degree of Electrical Engineering from Department of Electrical Engineering and Information Technology, Gadjah Mada University in 2016. His research topics are focused on design and analysis of electrical machine. He is currently conducting research about linear permanent magnet generator to be applied in South Coast of Yogyakarta, Indonesia.

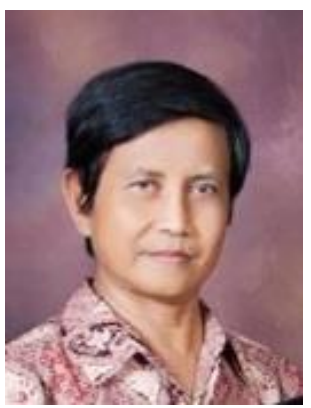

Harnoko Stephanus, born on December 1953 in Yogyakarta, Indonesia. He got his Bachelor and Master degree, both from Electrical Engineering Major, Gadjah Mada University. He is currenly a lecturer at the Department of Electrical Engineering and Information Technology, Gadjah Mada University. His research is specialized in Energy management System, Electrical Energy Conservation, Distributed System. 